Article

\title{
LeTetR Positively Regulates 3-Hydroxylation of the Antifungal HSAF and Its Analogs in Lysobacter enzymogenes OH11
}

\author{
Lingjun $\mathrm{Yu}^{1,2,+}$, Vimmy Khetrapal ${ }^{1,+}$, Fengquan Liu ${ }^{2}$ and Liangcheng Du ${ }^{1, * *()}$ \\ 1 Department of Chemistry, University of Nebraska-Lincoln, Lincoln, NE 68588-0304, USA; \\ LingjunYu113@outlook.com (L.Y.); vimmyjagga@gmail.com (V.K.) \\ 2 Institute of Plant Protection, Jiangsu Academy of Agricultural Sciences, Nanjing 210014, China; \\ fqliu20011@sina.com \\ * Correspondence: ldu3@unl.edu; Tel.: +1-402-472-2998 \\ + These authors contributed equally to this work.
}

Academic Editors: Daniel Krug and Lena Keller

Received: 14 April 2020; Accepted: 12 May 2020; Published: 13 May 2020

\begin{abstract}
The biocontrol agent Lysobacter enzymogenes $\mathrm{OH} 11$ produces several structurally distinct antibiotic compounds, including the antifungal HSAF (Heat Stable Antifungal Factor) and alteramides, along with their 3-dehydroxyl precursors (3-deOH). We previously showed that the 3-hydroxylation is the final step of the biosynthesis and is also a key structural moiety for the antifungal activity. However, the procedure through which $\mathrm{OH} 11$ regulates the 3-hydroxylation is still not clear. In OH11, the gene orf3232 was predicted to encode a TetR regulator (LeTetR) with unknown function. Here, we deleted orf3232 and found that the LeTetR mutant produced very little HSAF and alteramides, while the 3 -deOH compounds were not significantly affected. The production of HSAF and alteramides was restored in orf3232-complemented mutant. qRT-PCR showed that the deletion of orf3232 impaired the transcription of a putative fatty acid hydroxylase gene, orf2195, but did not directly affect the expression of the HSAF biosynthetic gene cluster (hsaf). When an enzyme extract from E. coli expressing the fatty acid hydroxylase gene, hsaf-orf7, was added to the LeTetR mutant, the production of HSAF and alteramides increased by 13-14 fold. This study revealed a rare function of the TetR family regulator, which positively controls the final step of the antifungal biosynthesis and thus controls the antifungal activity of the biocontrol agent.
\end{abstract}

Keywords: natural product; HSAF; alteramides; regulation; Lysobacter enzymogenes

\section{Introduction}

Lysobacter is a genus of Gram-negative gliding bacteria inhabiting soil and fresh water [1]. Natural products with distinct chemical structures and biological activities have been identified from the Lysobacter species that are recognized as a new source of antibiotics (Figure 1A) [2]. HSAF belonging to the family of polycyclic tetramate macrolactams (PoTeM) is a predominate natural product of Lysobacter enzymogenes [3,4]. It exhibits a broad-spectrum antifungal activity with a novel mode of action and has the potential as a novel lead compound for fungicides or antifungal drugs [5-7].

The regulation of HSAF biosynthesis involves a complex network including two-component regulatory systems (TCS), transcription regulators, and small-molecule signaling factors. Previous studies showed that several signal pathways, such as the TCS Rpf/DSF (diffusible signal factor), DF (diffusible factor), and Clp (cyclic adenosine monophosphate-receptor-like protein), are critical to the biosynthesis of HSAF [8-18]. In the Rpf/DSF pathway, the signal molecule LeDSF3 promotes the HSAF production and Clp expression [8]. In the DF pathway, the LysR-family regulator LysR $\mathrm{Le}_{\mathrm{Le}}$ binds to 
the promoter region of HSAF biosynthetic gene and induces the gene expression and HSAF production, after binding with its ligand 4-hydroxybenzoic acid (4-HBA) [11]. In addition, the MarR-family regulator LarR promotes the HSAF biosynthesis by binding to the promoter region of the HSAF biosynthetic gene, and is negatively controlled by $4-\mathrm{HBA}$ but positively controlled by LysR $\mathrm{Le}_{\mathrm{Le}}$ [12]. In the Clp pathway, an acetyltransferase Lat that is regulated by Clp is involved in the HSAF biosynthesis [10]. A TetR-family regulator LetR inhibits the HSAF biosynthetic genes expression and HSAF production by binding to the promoter of the biosynthetic gene [13]. The TCS response regulator PilG negatively controls the HSAF production, while another TCS response regulator PilR induces the biosynthesis of HSAF by affecting the in vivo concentration of cyclic di-GMP [14,15]. Cyclic di-GMP regulates the HSAF biosynthesis by controlling the binding of Clp with its binding sites in the HSAF promoter [16] and maintaining a proper cellular concentration of spermidine, which is shown to be critical to the HSAF production $[17,18]$. Overall, the previous studies mainly focused on the regulation of the final product HSAF of the biosynthetic pathway.

Apart from HSAF, L. enzymogenes also produces several PoTeM analogs including alteramides and their 3-dehydroxy forms, 3-deOH HSAF, and 3-deOH alteramides (Figure 1A). Our previous study has shown that 3-hydroxylation is the final step in the biosynthesis of PoTeM, and the fatty acid hydroxylase SD that is encoded by orf7 of the hsaf gene cluster is required for the 3-hydroxylation [19]. The study also indicated that the 3-OH moiety is critical to the antifungal activity of HSAF. However, it remains unclear as to how L. enzymogenes controls the production of the active 3-OH compounds versus the barely active 3-deOH compounds. In this work, we found that a new TetR-family regulator, LeTetR encoded by orf3232 in L. enzymogenes OH11, positively regulates the 3-hydroxylation of HSAF and its analogs, but does not affect the production of 3-deOH HSAF and 3-deOH alteramides.

\section{Results}

\subsection{LeTetR Regulates the Production of HSAF and Alteramides}

Genome annotation of L. enzymogenes OH11 predicted that orf3232 encodes a TetR regulator (here named LeTetR). LeTetR contained the DNA-binding domain at the C-terminus and RutR domain, which might be related to the ligand binding at the $N$-terminus (Figure S1). Since the TetR family regulators are known to regulate antibiotics production, we deleted the orf3232 gene ( $\triangle \mathrm{ORF} 3232)$ (Figure S2) and examined the impact on the production of the most predominant antibiotics in strain $\mathrm{OH} 11, \mathrm{HSAF}$, and the analogs (Figure 1A). HPLC analysis showed that the production of HSAF and alteramides in $\triangle \mathrm{ORF} 3232$ decreased significantly, to about $20 \%$ of that in the wild type (WT), while the production of 3-deOH HSAF and 3-deOH alteramides increased slightly (Figure 1B,C). When the orf3232 gene was reintroduced into the mutant, the complementary strain (ORF3232CM) (Figure S3) restored the production of HSAF and alteramides to the WT level, while the level of 3-deOH HSAF and 3-deOH alteramides was nearly unaffected in ORF3232CM (Figure 1B,C). 
A

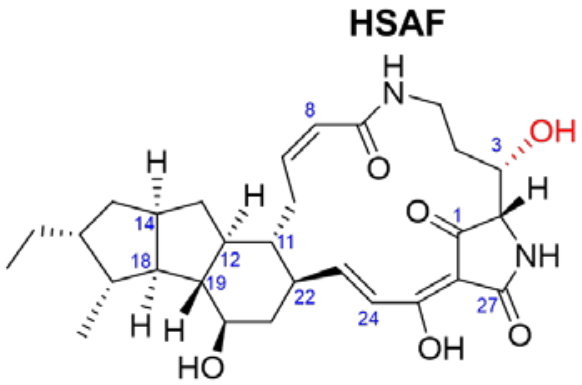

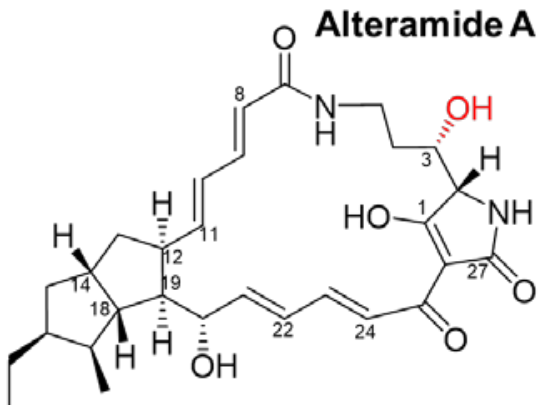

B

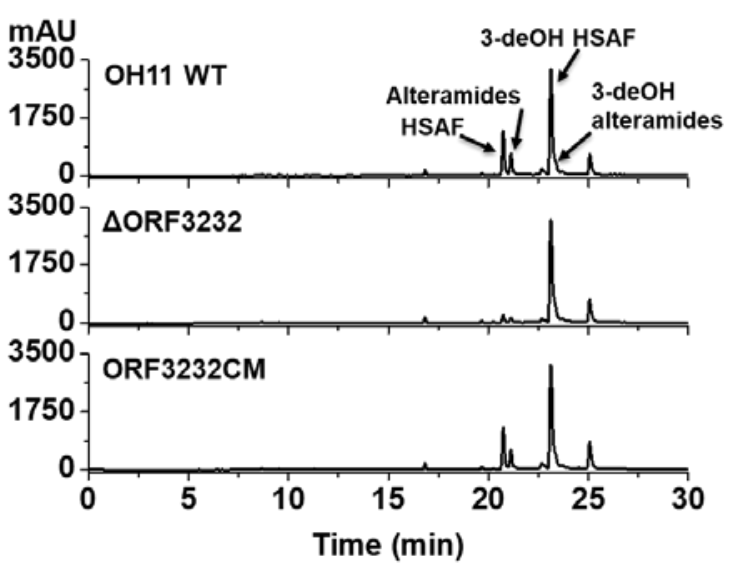

3-deOH HSAF

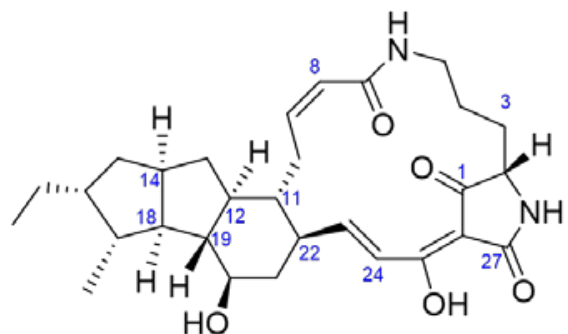

Alteramide B

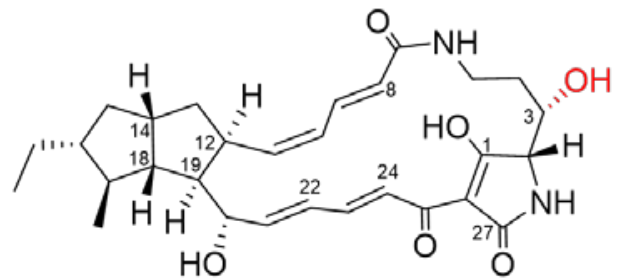

C

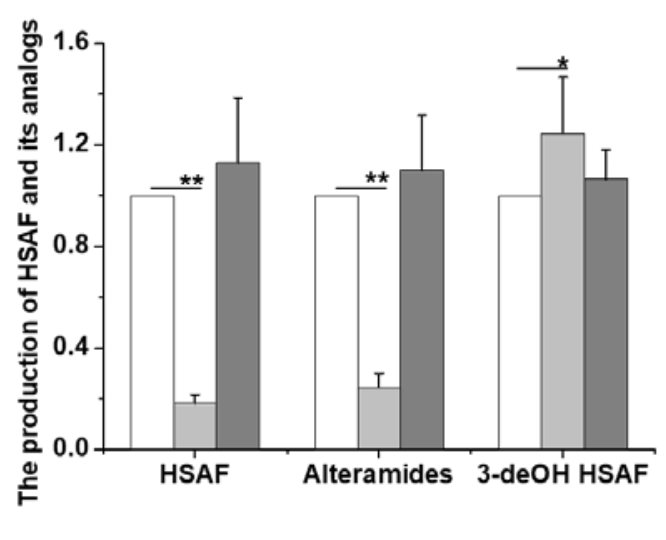

Figure 1. The antifungal HSAF and its analogs and impact of the deletion of the TetR family regulator, LeTetR, on their production in L. enzymogenes OH11. (A) Chemical structure of HSAF and its analogs produced in L. enzymogenes OH11. (B) HPLC analysis of HSAF and its analogs in strains WT, $\triangle$ ORF3232 and ORF3232CM cultured in 1/10 TSB (Tryptic Soy Broth) medium for $48 \mathrm{~h}$. (C) Quantification of HSAF and its main analogs in these strains. Note: As the 3-deOH alteramides were minor compounds and not well resolved from 3-deOH HSAF in HPLC, only 3-deOH HSAF was presented in the quantification. White columns, WT; light-gray columns, $\triangle$ ORF3232; dark-gray columns, ORF3232CM. Data are presented as averages of three independent experiments, each conducted in triplicates, with * $p<0.05$; ** $p<0.01$.

The results indicated that LeTetR might participate in the regulation of the 3-hydroxylation of HSAF and alteramides. Our previous study showed that orf7 (fatty acid hydroxylase gene, or SD gene) in the HSAF biosynthetic gene cluster (hsaf) is required for the 3-hydroxylation of HSAF, and orf8 (ferredoxin reductase gene, or the FNR gene) enhanced this process [19]. We thus suspected that LeTetR might regulate the transcription of orf 7 and orf8 to affect the production of the 3-hydroxyl compounds, HSAF and alteramides. Surprisingly, qRT-PCR results showed that the transcription of orf7 and orf8, as well as the HSAF polyketide-nonribosomal peptide synthetase gene, hsaf-pks-nrps, was not significantly changed in the mutant strain $\triangle \mathrm{ORF} 3232$ (Figure S4). This led us to search for other 
putative fatty acid hydroxylase genes, outside the HSAF biosynthetic gene cluster. Three candidate genes (orf2195, orf4890, and orf5031) were found from the OH11 genome (Figure S5). The transcription of orf 2195 was significantly decreased in the strain $\triangle \mathrm{ORF} 3232$ and restored to the WT level in the strain ORF3232CM, when cultured for $9 \mathrm{~h}$, and then almost could not be detected in all three strains, after $24 \mathrm{~h}$ and $36 \mathrm{~h}$ (Figure 2). In contrast, the transcription of orf4890 and orf5031 did not change significantly between strain $\triangle \mathrm{ORF} 3232$ and ORF3232CM (Figure 2).
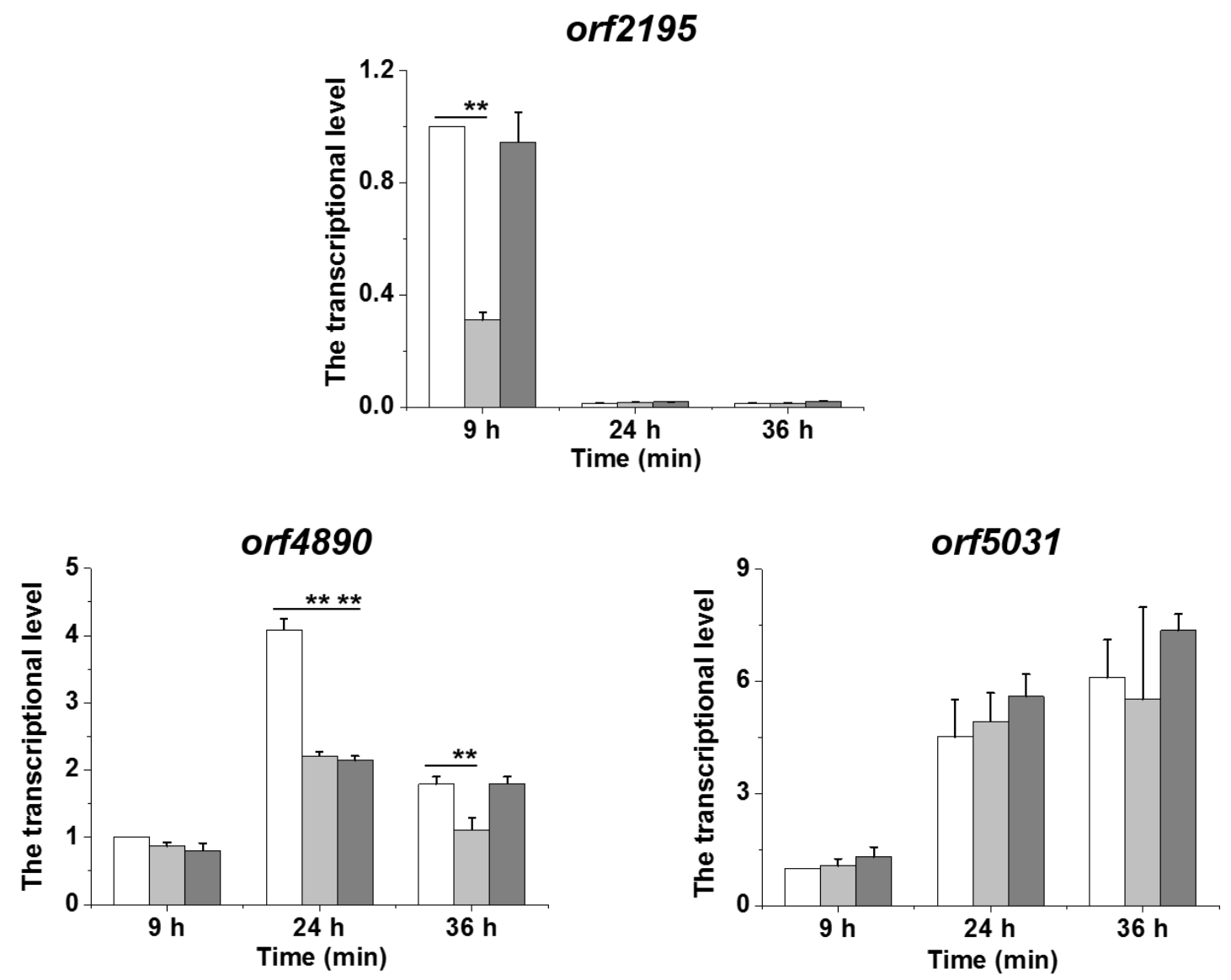

Figure 2. Transcription analysis of fatty acid hydroxylase genes (orf2195, orf4890, and orf5031) in OH11 cultured in 1/10 TSB medium. White columns, WT; light-gray columns, $\triangle$ ORF3232; and dark-gray columns, ORF3232CM. Data are presented as averages of the three independent experiments, each conducted in triplicates, with ${ }^{* *} p<0.01$.

The result suggested that the LeTetR positively regulated the transcription of orf2195, and ORF2195 in turn might also contribute to the conversion of 3-deOH HSAF and 3-deOH alteramides to HSAF and

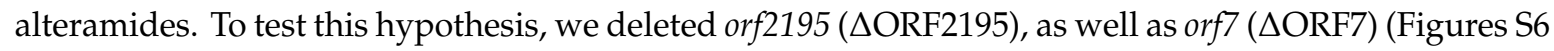
and S7) and analyzed the compounds in the deletion mutants. The HPLC results showed that the level of the compounds in strain $\triangle \mathrm{ORF} 2195$ was similar to that in WT, indicating orf2195 alone did not play a significant role in the 3-hydroxylation (Figure 3). However, the level of HSAF and alteramides in strain $\triangle \mathrm{ORF7}$ was significantly reduced, while the level of 3-deOH HSAF (also probably 3-deOH alteramides) increased slightly (Figure 3). The result is consistent with the previous study [19] and revealed that, while ORF7 (SD) is the main enzyme for 3-hydroxylation, other fatty acid hydroxylases, such as ORF2195, are also likely to contribute to the conversion of 3-deOH compounds to HSAF and alteramides (Figure 3). Finally, we generated a double deletion mutant ( $\triangle$ ORF7-ORF2195), by deleting both orf2195 and orf7 (Figure S8). The level of HSAF and alteramides in strain $\triangle$ ORF7-ORF2195 further decreased when compared to that of strain $\triangle$ ORF7 or strain ORF2195 (Figure 3), supporting that ORF2195 plays a role in HSAF 3-hydroxylation. 
A

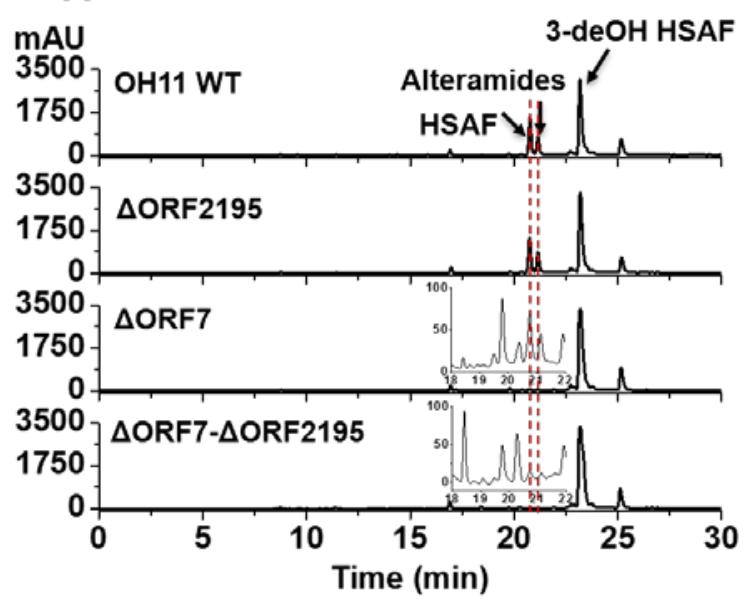

B

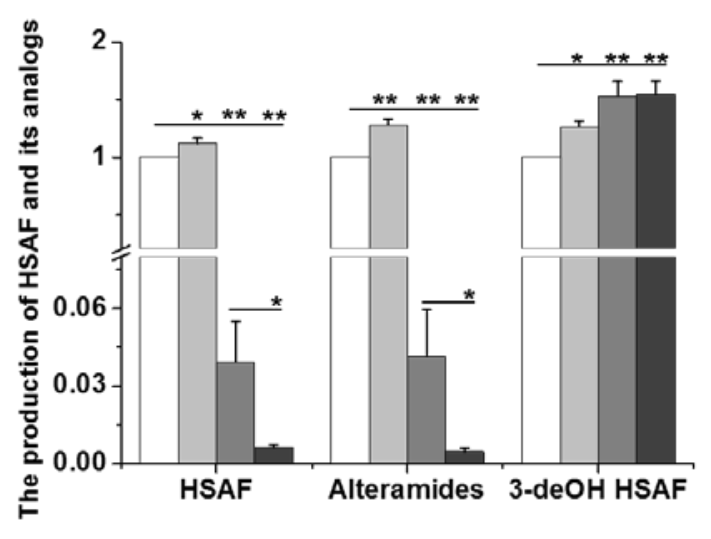

Figure 3. Production of HSAF and its analogs in deletion mutants of fatty acid hydroxylase genes in L. enzymogenes OH11. (A) HPLC analysis of HSAF and its analogs in strains WT, $\triangle$ ORF2195, $\triangle$ ORF7, and $\triangle$ ORF7- $\triangle$ ORF2195, cultured in 1/10 TSB medium for $48 \mathrm{~h}$. (B) Quantification of HSAF and its analogs in these strains. White columns, WT; light-gray columns, $\triangle$ ORF2195; medium-gray columns, $\triangle$ ORF7; dark-grey columns, $\triangle$ ORF7- $\triangle$ ORF2195. Note: As the 3-deOH alteramides were minor compounds and not well-resolved from 3-deOH HSAF in HPLC, only 3-deOH HSAF was presented in the quantification. Data are presented as the averages of the three independent experiments, each conducted in triplicates, with * $p<0.05 ; * *<0.01$.

2.2. Bioconversion of 3-deOH Compounds in the LeTetR Mutant to HSAF and Alteramides Using an Enzyme Extract from the E. coli-Expressing orf7 Gene

The above results confirmed that the fatty acid hydroxylase encoded by orf7 (SD gene) in the HSAF biosynthetic gene cluster is the main player in the 3-hydroxylation of HSAF. This inspired us to test the bioconversion of the 3-deOH compounds produced in the LeTetR mutant, $\triangle \mathrm{ORF} 3232$, using the E. coli-carrying hsaf-orf7 gene. When the E. coli extract was added to the Lysobacter culture of $\triangle \mathrm{ORF} 3232$, HSAF and alteramides dramatically increased (14-fold and 13-fold, respectively) in the $\triangle$ ORF3232 culture. In addition, the 3 -deOH compounds remained at a high level in $\triangle \mathrm{ORF} 3232$, with the addition of the E. coli enzyme extract (Figure 4). This showed that the Lysobacter strain $\Delta$ ORF3232 continually produced the 3-deOH compounds, while a large portion of the 3-deOH compounds were converted to HSAF and alteramides by the E. coli-expressed enzyme. The results confirmed the 3-hydroxylation function of $h s a f$-orf7 and also revealed a potentially robust bioconversion for production of the active PoTeM compounds (HSAF and alteramides), by using the LeTetR mutant as a cell factory. 
A

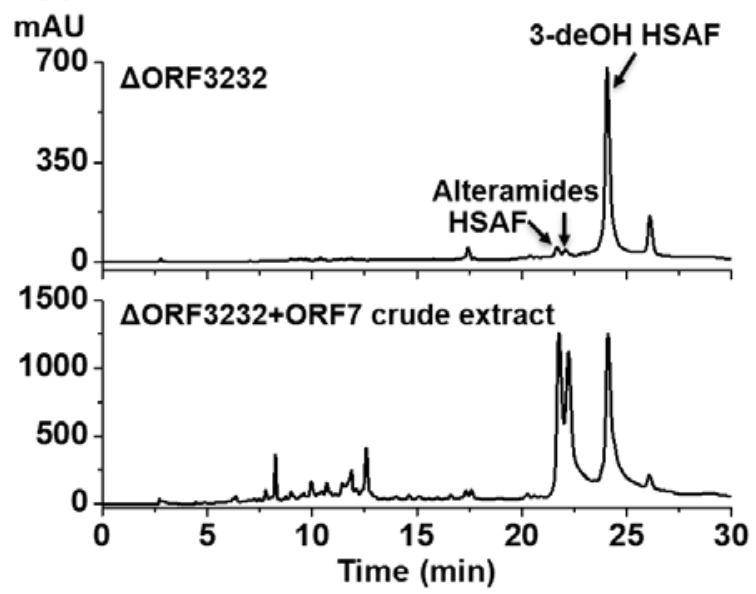

B

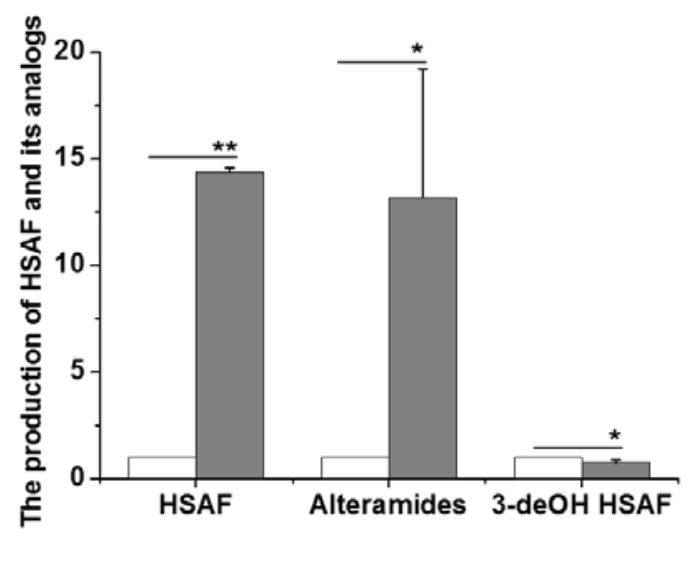

Figure 4. Bioconversion of 3-deOH compounds to HSAF and alteramides. (A) HPLC analysis of HSAF and its analogs in the LeTetR mutant, $\triangle$ ORF3232, with or without addition of an enzyme extract from the E. coli-expressing hsaf-orf7. $\triangle$ ORF3232 was cultured in 1/10 TSB medium for $72 \mathrm{~h}$. (B) Quantification of HSAF and its analogs in the cultures. Note: As the 3-deOH alteramides were minor compounds and not well-resolved from 3-deOH HSAF in HPLC, only 3-deOH HSAF was presented in the quantification. White columns, $\triangle$ ORF3232 without the enzyme extract; gray columns, $\triangle$ ORF3232 with the enzyme extract. Data are presented as averages of three independent experiments, each conducted in triplicates, with * $p<0.05 ;{ }^{* *} p<0.01$.

\section{Discussion}

The TetR family regulators are typically repressor proteins that negatively control the gene expression in many cellular processes, such as antibiotic resistance, biosynthesis, pathogenesis, and response to cell stress [20]. In this study, we investigated the function of a TetR regulator (LeTetR) encoded by orf3232 in L. enzymogenes OH11. When this gene was deleted, the production of the 3-hydroxyl products, HSAF and alteramides, was significantly reduced, while the production of their biosynthetic precursors, 3-deOH HSAF and 3-deOH alteramides, was not apparently affected (Figure 1). This shows that LeTetR positively regulates the 3-hydroxylation step in the production of this family of antifungal natural products. It also suggests that LeTetR might selectively control the final step in the biosynthesis, which is key to the conversion of the barely active precursors, the 3-deOH compounds, to the highly active final products-HSAF and alteramides. Wang et al. previously studied a TetR regulator (LetR) in OH11, which is encoded by orf0953 [13]. Their results showed that LetR negatively regulated HSAF production, through a transcription repression by directly binding to the promoter ( $\mathrm{P}_{\mathrm{HSAF}}$ ) of the HSAF biosynthetic gene cluster. The LetR-regulated HSAF biosynthesis was due to the direct control of the transcription of the biosynthetic gene (including the key biosynthetic gene hsaf-pks-nrps). However, our results show that LeTetR did not appear to directly affect the transcription of hsaf-pks-nrps, or the associated genes in the cluster, such as orf7 (SD gene) and orf8 (FNR gene) for 3-hydroxylation (Figure S4). In search for other putative fatty acid hydroxylase genes that might be controlled by LeTetR and so might contribute to the 3-hydroxylation, we found the transcription of one gene, orf2195, was clearly impaired upon deletion and restored upon complementation of the regulator LeTetR gene, orf3232 (Figure 2). However, orf2195 appeared to play a minor role in the 3-hydroxylation, because the deletion of orf 2195 only had a minor effect on the 3-hydroxyl products. When both orf 2195 and orf7 were deleted, the 3-hydroxyl products were barely detectable, while the accumulation of the 3 -deOH products increased in the double deletion mutant (Figure 3). Together, the results revealed an unusual TetR type regulator that positively controlled the final step of the HSAF biosynthetic pathway.

Despite the interesting findings, it should be pointed out that the exact mechanism by which LeTetR selectively controls the 3-hydroxylation step in the biosynthesis of HSAF is not completely 
understood. The results showed that the transcription level of the orf 7 gene was not affected in the orf3232 mutant $\triangle \mathrm{ORF} 3232$, which mainly produced the 3-deOH precursors, with very little final products (HSAF and alteramides). However, ORF7 is the main enzyme to convert the 3-deOH precursors to the final products. The underlying mechanism for this observation is unclear, but one possibility could be that orf3232 might regulate the translation or catalytic activity of the ORF7 enzyme. The decreased level of HSAF and alteramides in the orf3232 mutant might be due to a decrease of the functional enzymes, which was rescued by the E. coli-produced ORF7. More studies are needed to tackle this fairly unusual LeTetR encoded by orf3232, which could reveal new insights into the function of the TetR family regulators. Nevertheless, our results showed that the strain $\triangle \mathrm{ORF} 3232$ could be used as a cell factory to generate the $3-\mathrm{deOH}$ compounds, which are inactive precursors of the final antifungal compounds, HSAF and alteramides. The wild-type $\mathrm{OH} 11$ produced a complex of HSAF and analogs, which are controlled by a network of regulators and signals [8-18]. Small changes in culture conditions could affect the production of the compounds. In contrast, strain $\triangle$ ORF3232 produced a relatively simple profile of compounds. Moreover, after the ORF7 extract was added to the strain $\triangle \mathrm{ORF} 3232$, the yield of the 3-deOH precursors decreased only slightly $(\sim 75 \%$ of that without ORF7 extract), while the yield of HSAF and alteramides increased dramatically (14-fold and 13-fold, respectively) (Figure 4). This indicated that exogenous ORF7 could not only convert the 3-deOH precursors to the final compounds, but could also drive the strain $\triangle \mathrm{ORF} 3232$ to continuously produce these precursors. Thus, the overall yield of HSAF and alteramides could be significantly enhanced using this method.

\section{Materials and Methods}

\subsection{Bacterial Strains, Plasmids, and Growth Conditions}

The bacterial strains and plasmids used in this study are shown in Table S1. The Luria-Bertani (LB) broth medium was used for the growth of L. enzymogenes OH11 (CGMCC No. 1978). 1/10 TSB ( $3 \mathrm{~g}$ TSB, per liter) was used for the RNA extraction and HSAF production. Plasmid pJQ200SK was used for gene deletion and complementary in L. enzymogenes OH11 [21]. The Escherichia coli strain XL-1 Blue was cultured at $37^{\circ} \mathrm{C}$ in the LB medium supplemented with gentamicin $(\mathrm{Gm}, 50 \mathrm{~g} / \mathrm{mL})$ to propagate plasmids. E. coli strain S17 was used for intergeneric conjugation. E. coli strain BL21 (DE3)/ORF7 was used for the ORF7 expression.

\subsection{DNA Manipulation and Lysobacter Transformation}

Chromosomal DNA and plasmids were isolated from L. enzymogenes OH11 or E. coli, according to the standard techniques. Database search and sequence analysis were performed using the online program PSI-BLAST. For the Lysobacter transformation, the recombination plasmid was introduced into L. enzymogenes OH11 through intergeneric conjugation, using E. coli strain S17. After growing on LB plates with Kanamycin $(\mathrm{Km}, 100 \mu \mathrm{g} / \mathrm{mL})$ and Gentamicin $(\mathrm{Gm}, 150 \mu \mathrm{g} / \mathrm{mL})$ at $30{ }^{\circ} \mathrm{C}$ for $72 \mathrm{~h}$, the transformants were plated on the LB plates supplemented with $10 \%(w / v)$ sucrose and $\mathrm{Km}$ $(100 \mu \mathrm{g} / \mathrm{mL})$. After growing at $30^{\circ} \mathrm{C}$ for $72 \mathrm{~h}$, the colonies were transferred into the LB plates containing $\mathrm{Km}(100 \mu \mathrm{g} / \mathrm{mL})$ or $\mathrm{Km}(100 \mu \mathrm{g} / \mathrm{mL})+\mathrm{Gm}(150 \mu \mathrm{g} / \mathrm{mL})$. Finally, the Km-resistant and Gm-sensitive strains were selected for PCR verification.

\subsection{Primers and $P C R$}

All primers used in this study were listed in Table S2. Phusion High-Fidelity DNA polymerase (Thermo Scientific, Waltham, MA, USA) and Taq DNA polymerase (Thermo Scientific, Waltham, MA, USA) were used for PCR program. For Phusion DNA polymerase, an initial denaturation at $98^{\circ} \mathrm{C}$ for $30 \mathrm{~s}$ was followed by 30 cycles of amplification $\left(98^{\circ} \mathrm{C}\right.$ for $10 \mathrm{~s}, 60^{\circ} \mathrm{C}$ for $15 \mathrm{~s}, 72^{\circ} \mathrm{C}$ for $\left.1 \mathrm{~min}\right)$, and additional $5 \mathrm{~min}$ at $72{ }^{\circ} \mathrm{C}$. For Taq DNA polymerase, an initial denaturation at $95^{\circ} \mathrm{C}$ for $3 \mathrm{~min}$ was followed by 30 cycles of amplification $\left(95^{\circ} \mathrm{C}\right.$ for $30 \mathrm{~s}, 60^{\circ} \mathrm{C}$ for $30 \mathrm{~s}, 72^{\circ} \mathrm{C}$ for $\left.1 \mathrm{~min}\right)$, and an additional 
10 min at $72{ }^{\circ} \mathrm{C}$. Considering different DNA templates and primers, the annealing temperature and the elongation time were changed in some cases.

\subsection{Generation of the Deletion Mutant of orf3232 and Its Complementary Strain}

The DNA fragments corresponding to the upstream and downstream region of orf3232 were amplified using ORF3232UF/UR and ORF3232DF/DR. After treating the upstream region with XhoI/SpeI, and treating the downstream region with $B a m \mathrm{HI} / \mathrm{XhoI}$, the two DNA fragments were ligated into the BamHI/SpeI sites of the plasmid pJQ200SK, to generate the recombination plasmid pJQ200SK::ORF3232. The plasmid was introduced into L. enzymogenes $\mathrm{OH} 11$ through intergeneric conjugation. After antibiotic and sucrose screening, the transformants were used for PCR verification by primers ORF3232DF/UR and ORF3232VFI/VRI (Figure S2).

For complementary analysis, the DNA fragment containing the upstream region, the downstream region, and the orf3232 gene was amplified using primers ORF3232CF/UR. Then, the fragment was treated with XhoI/SpeI and ligated into the same sites of plasmid pJQ200SK, to generate the recombination plasmid pJQ200SK::ORF3232C. The recombination plasmid was transferred into the $\triangle$ ORF3232 strain through intergeneric conjugation. After antibiotic and sucrose screening, the transformants were used for PCR verification using primers ORF3232DF/UR and ORF3232VFI/VRI (Figure S3).

\subsection{Construction of the Deletion Mutant of Fatty Acid Hydroxylase Genes}

The DNA fragments corresponding to the upstream and downstream region of the fatty acid hydroxylase genes (orf2195 or orf7 in HSAF biosynthetic gene cluster) were amplified using the primers listed in Table S2. After treating with the restriction enzymes, the two DNA fragments were ligated into the ApaI/SpeI sites of plasmid pJQ200SK, to generate the recombination plasmid pJQ200SK::ORF2195 or pJQ200SK::ORF7. The plasmid was introduced into L. enzymogenes OH11 through intergeneric conjugation. After antibiotic and sucrose screening, the transformants were used for PCR verification through the primers listed in Table S2 (Figures S6 and S7). To construct the double deletion mutant orf7 and orf2195, the plasmid pJQ200SK::ORF2195 was introduced into $\triangle$ ORF7 strain through intergeneric conjugation. After antibiotic and sucrose screening, the transformants were used for PCR verification by the primers listed in Table S2 (Figure S8).

\subsection{RNA Extraction and Real-Time PCR}

RNA was isolated from the OH11 WT, $\triangle \mathrm{ORF} 3232$, and ORF3232CM strains cultured in 1/10 TSB medium for 9, 24, and $36 \mathrm{~h}$, as described previously [22]. After removing the contaminated DNA using DNase I (Thermo Scientific, Waltham, MA, USA), RNA was reverse transcribed to the complementary DNA using SuperScript ${ }^{\mathrm{TM}}$ II RT reagent kit (Invitrogen, Carlsbad, CA, USA). Real-time PCR was carried out in the CFX Connect Real-Time PCR Detection System (BIO-RAD Laboratories, Inc, Hercules, CA, USA) using PowerUp SYBR Green Master Mix (Applied Biosystems, Foster, CA, USA), using the primers listed in Table S2. The conditions were used as follows- $50{ }^{\circ} \mathrm{C}$ for $2 \mathrm{~min}, 95^{\circ} \mathrm{C}$ for $2 \mathrm{~min}$, followed by 40 cycles of $95^{\circ} \mathrm{C}$ for $15 \mathrm{~s}$ and $60^{\circ} \mathrm{C}$ for $1 \mathrm{~min}$. The $16 \mathrm{~S}$ rRNA was used as an internal control. The relative transcriptional levels of the tested genes were normalized to 16S rRNA and determined using the $2^{-\triangle \Delta \mathrm{CT}}$ method [23].

\subsection{Extraction and HPLC Analysis of HSAF and Its Analogs}

OH11 WT, $\triangle \mathrm{ORF} 3232$, and ORF3232CM strains were incubated into $1 \mathrm{~mL} \mathrm{LB}$ at $30{ }^{\circ} \mathrm{C}$ with overnight shaking at $200 \mathrm{rpm}$. An aliquot (1\%) of the cultures was transferred to $25 \mathrm{~mL} \mathrm{1/10} \mathrm{TSB}$, at $30{ }^{\circ} \mathrm{C}$ with shaking at $200 \mathrm{rpm}$, for $48 \mathrm{~h}$. The culture broths were treated with $75 \mu \mathrm{L}$ formic acid and $25 \mathrm{~mL}$ ethyl acetate. The organic phase was dried with the air flow, and the residues were re-dissolved in $200 \mu \mathrm{L}$ methanol. A $20 \mu \mathrm{L}$ aliquot of each extract was analyzed by HPLC (Agilent, 1220 Infinity LC, Santa Clara, CA, USA). Water/0.05\% formic acid (solvent A) and acetonitrile/0.05\% formic acid (solvent $\mathrm{B}$ ) were used as the mobile phases with a flow rate of $1.0 \mathrm{~mL} / \mathrm{min}$. The HPLC program was as 
follows $-5-25 \%$ B in $0-5 \mathrm{~min}, 25-80 \% \mathrm{~B}$ in $5-25 \mathrm{~min}, 80-100 \%$ B in $25-26 \mathrm{~min}$, maintained to $28 \mathrm{~min}$, back to $5 \%$ B at $29 \mathrm{~min}$, and maintained to $30 \mathrm{~min}$. HSAF and its analogs were detected at $318 \mathrm{~nm}$ on a UV detector.

\subsection{Preparation of Protein Crude Extract Containing ORF7}

The strain BL21 (DE3)/ORF7 [19] was incubated into LB containing $50 \mu \mathrm{g} / \mathrm{mL}$ kanamycin, and the culture was grown at $37^{\circ} \mathrm{C}$ with shaking at $250 \mathrm{rpm}$. When the optical density $\left(\mathrm{OD}_{600}\right)$ of the culture reached $0.6-0.7$, the protein expression was induced with $1 \mathrm{mM}$ IPTG. The cells were allowed to further grow for $15 \mathrm{~h}$ at $16^{\circ} \mathrm{C}$. Finally, the cells were harvested through centrifugation at $4{ }^{\circ} \mathrm{C}$ and resuspended in PBS $\left(0.24 \mathrm{~g} \mathrm{KH}_{2} \mathrm{PO}_{4}, 1.44 \mathrm{~g} \mathrm{Na}_{2} \mathrm{HPO}_{4}, 8 \mathrm{~g} \mathrm{NaCl}, 0.2 \mathrm{~g} \mathrm{KCl}, \mathrm{pH} 7.5\right.$, per liter), followed by sonication and centrifugation. The supernatant containing ORF7 was used as the enzyme crude extract.

\subsection{Exogenous Addition of the ORF7 Crude Extract to the $\triangle O R F 3232$ Strain}

$\triangle$ ORF3232 strain was incubated into $4 \mathrm{~mL} \mathrm{LB}$ at $30{ }^{\circ} \mathrm{C}$ with overnight shaking at $200 \mathrm{rpm}$. An aliquot (1\%) of the cultures was transferred to $25 \mathrm{~mL} \mathrm{1/10} \mathrm{TSB}$ at $30^{\circ} \mathrm{C}$, with shaking at $200 \mathrm{rpm}$ for $48 \mathrm{~h}$. After this, the ORF7 crude extract was added into the cultures, and incubated at $30{ }^{\circ} \mathrm{C}$ with shaking at $200 \mathrm{rpm}$ for $24 \mathrm{~h}$. Then, the production of HSAF and its analogs was extracted and analyzed using the above-mentioned method.

Supplementary Materials: The following are available online. Table S1: Bacterial strains and plasmids used in this study. Table S2: Primers used in this study. Figure S1: The conserved domains in ORF3232. Figure S2: Deletion of orf3232. Figure S3: Complementary strain of $\triangle$ ORF3232. Figure S4: Transcriptional analysis of the HSAF biosynthetic genes, pks-nrps, orf7 and orf8. Figure S5: Alignment of the amino acid sequences of the putative fatty acid hydroxylases in OH11. Figure S6: Deletion of orf2195. Figure S7: Deletion of orf7 of the HSAF biosynthetic gene cluster. Figure S8: Deletion of both orf7 and orf2195.

Author Contributions: L.D., L.Y., and F.L. conceived the ideas; L.Y. and V.K. carried out experiments and data analysis; and L.Y. and L.D. wrote the manuscript. All authors have read and agreed to the published version of the manuscript.

Funding: This research was funded in part by the University of Nebraska Collaboration Initiative Seed Grant, and the Nebraska Public Power District through the Nebraska Center for Energy Sciences Research at the University of Nebraska-Lincoln.

Acknowledgments: We thank Jiangsu Academy of Agricultural Sciences for the postdoctoral fellowship to L.Y.

Conflicts of Interest: The authors declare no conflict of interest.

\section{References}

1. Christensen, P.; Cook, F.D. Lysobacter, a new genus of non-fruiting, gliding bacteria with a high base ratio. Int. J. Syst. Bacteriol. 1978, 28, 367-393. [CrossRef]

2. Xie, Y.; Wright, S.; Shen, Y.; Du, L. Bioactive natural products from Lysobacter. Nat. Prod. Rep. 2012, 19, 1277-1287. [CrossRef] [PubMed]

3. Yu, F.; Zaleta-Rivera, K.; Zhu, X.; Huffman, J.; Millet, J.C.; Harris, S.D.; Yuen, G.; Li, X.C.; Du, L. Structure and biosynthesis of heat-stable antifungal factor (HSAF), a broad-spectrum antimycotic with a novel mode of action. Antimicrob. Agents Chemother. 2007, 51, 64-72. [CrossRef] [PubMed]

4. Lou, L.; Qian, G.; Xie, Y.; Hang, J.; Chen, H.; Zaleta-Rivera, K.; Li, Y.; Shen, Y.; Dussault, P.H.; Liu, F.; et al. Biosynthesis of hsaf, a tetramic acid-containing macrolactam from Lysobacter enzymogenes. J. Am. Chem. Soc. 2011, 133, 643-645. [CrossRef]

5. Li, S.; Du, L.; Yuen, G.; Harris, S.D. Distinct ceramide synthases regulate polarized growth in the filamentous fungus Aspergillus nidulans. Mol. Biol. Cell 2006, 17, 1218-1227. [CrossRef]

6. Ding, Y.; Li, Z.; Li, Y.; Lu, C.; Wang, H.; Shen, Y.; Du, L. HSAF-induced antifungal effects in Candida albicans through ROS-mediated apoptosis. RSC Adv. 2016, 6, 30895-30904. [CrossRef]

7. Ding, Y.; Li, Y.; Li, Z.; Zhang, J.; Lu, C.; Wang, H.; Shen, Y.; Du, L. Alteramide B is a microtubule antagonist of inhibiting Candida albicans. Biochim. Biophys. Acta 2016, 1860, 2097-2106. [CrossRef] 
8. Han, Y.; Wang, Y.; Tombosa, S.; Wright, S.; Huffman, J.; Yuen, G.; Qian, G.; Liu, F.; Shen, Y.; Du, L. Identification of a small molecule signaling factor that regulates the biosynthesis of the antifungal polycyclic tetramate macrolactam HSAF in Lysobacter enzymogenes. Appl. Microbiol. Biotechnol. 2015, 99, 801-811. [CrossRef] [PubMed]

9. Qian, G.; Wang, Y.; Liu, Y.; Xu, F.; He, Y.W.; Du, L.; Venturi, V.; Fan, J.; Hu, B.; Liu, F. Lysobacter enzymogenes uses two distinct cell-cell signaling systems for differential regulation of secondary-metabolite biosynthesis and colony morphology. Appl. Environ. Microbiol. 2013, 79, 6604-6616. [CrossRef] [PubMed]

10. Wang, Y.; Zhao, Y.; Zhang, J.; Zhao, Y.; Shen, Y.; Su, Z.; Xu, G.; Du, L.; Huffman, J.M.; Venturi, V.; et al. Transcriptomic analysis reveals new regulatory roles of $\mathrm{Clp}$ signaling in secondary metabolite biosynthesis and surface motility in Lysobacter enzymogenes OH11. Appl. Microbiol. Biotechnol. 2014, 98, 9009-9020. [CrossRef] [PubMed]

11. Su, Z.; Chen, H.; Wang, P.; Tombosa, S.; Du, L.; Han, Y.; Shen, Y.; Qian, G.; Liu, F. 4-Hydroxybenzoic acid is a diffusible factor that connects metabolic shikimate pathway to the biosynthesis of a unique antifungal metabolite in Lysobacter enzymogenes. Mol. Microbiol. 2017, 104, 163-178. [CrossRef] [PubMed]

12. Su, Z.; Han, S.; Fu, Z.Q.; Qian, G.; Liu, F. Heat-stable antifungal factor (HSAF) biosynthesis in Lysobacter enzymogenes is controlled by the interplay of two transcription factors and a diffusible molecule. Appl. Environ. Microbiol. 2018, 84, e01754-17. [CrossRef] [PubMed]

13. Wang, P.; Chen, H.; Qian, G.; Liu, F. LetR is a TetR family transcription factor from Lysobacter controlling antifungal antibiotic biosynthesis. Appl. Microbiol. Biotechnol. 2017, 101, 3273-3282. [CrossRef] [PubMed]

14. Zhou, X.; Qian, G.; Chen, Y.; Du, L.; Liu, F.; Yuen, G.Y. PilG is involved in the regulation of twitching motility and antifungal antibiotic biosynthesis in the biological control agent Lysobacter enzymogenes. Phytopathology 2015, 105, 1318-1324. [CrossRef] [PubMed]

15. Chen, Y.; Xia, J.; Su, Z.; Xu, G.; Gomelsky, M.; Qian, G.; Liu, F. Lysobacter PilR, the regulator of type IV pilus synthesis, controls antifungal antibiotic production via a cyclic di-GMP pathway. Appl. Environ. Microbiol. 2017, 83, e03397-16. [CrossRef] [PubMed]

16. Xu, G.; Han, S.; Huo, C.; Chin, K.H.; Chou, S.H.; Gomelsky, M.; Qian, G.; Liu, F. Signaling specificity in the c-di-GMP-dependent network regulating antibiotic synthesis in Lysobacter. Nucl. Acids Res. 2018, 46, 9276-9288. [CrossRef] [PubMed]

17. Chen, Y.; Yu, L.J.; Li, F.Q.; Du, L. Spermidine-regulated biosynthesis of heat-stable antifungal factor (HSAF) in Lysobacter enzymogenes OH11. Front. Microbiol. 2018, 9, 2984. [CrossRef]

18. Zhao, Y.; Zhang, T.T.; Ning, Y.; Shen, D.Y.; Yang, N.D.; Li, Y.; Chou, S.H.; Yang, L.; Qian, G. Spermidine plays a significant role in stabilizing a master transcription factor Clp to promote antifungal activity in Lysobacter enzymogenes. Appl. Microbiol. Biotechnol. 2019, 103, 1811-1822. [CrossRef]

19. Li, Y.; Huffman, J.; Li, Y.; Du, L.; Shen, Y. 3-Hydroxylation of the polycyclic tetramate macrolactam in the biosynthesis of antifungal HSAF from Lysobacter enzymogenes C3. MedChem Comm 2012, 9, 982-986. [CrossRef]

20. Ramos, J.L.; Martinez-Bueno, M.; Molina-Henares, A.J.; Teran, W.; Watanabe, K.; Zhang, X.D.; Gallegos, M.T.; Brennan, R.; Tobes, R. The TetR family of transcriptional repressors. Microbiol. Mol. Biol. Rev. 2005, 69, 326-358. [CrossRef]

21. Quandt, J.; Hynes, M.F. Versatile suicide vectors which allow direct selection for gene replacement in Gram-negative bacteria. Gene 1993, 127, 15-21. [CrossRef]

22. Liu, G.; Tian, Y.Q.; Yang, H.H.; Tan, H.R. A pathway-specific transcriptional regulatory gene for nikkomycin biosynthesis in Streptomyces ansochromogenes that also influences colony development. Mol. Microbiol. 2005, 55, 1855-1866. [CrossRef] [PubMed]

23. Livak, K.J.; Schmittgen, T.D. Analysis of relative gene expression data using real-time quantitative PCR and the 2(t)(-delta delta c) method. Methods 2001, 25, 402-408. [CrossRef] [PubMed]

Sample Availability: Samples of the compounds HSAF are available from the authors. 